\title{
X-ray Crystal Structure and EPR Spectra of "Arsenite-Inhibited" Desulfovibrio gigas Aldehyde Dehydrogenase: A Member of the Xanthine Oxidase Family
}

\author{
D. Roeland Boer, ${ }^{\dagger}$ Anders Thapper, ${ }^{\dagger}$ Carlos D. Brondino, ${ }^{\dagger}, \neq$ Maria J. Romão, ${ }^{*, \dagger}$ and \\ José J. G. Moura*,† \\ REQUIMTE-Departamento de Química, CQFB, Faculdade de Ciências e Tecnologia, \\ Universidade Nova de Lisboa, 2829-516 Caparica, Portugal, and Facultad de Bioquímica y Ciencias Biológicas, \\ Universidad Nacional del Litoral, Santa Fe, Argentina \\ Received February 20, 2004; E-mail:mromao@dq.fct.unl.pt, jose.moura@dq.fct.unl.pt
}

Aldehyde dehydrogenase (ADH, or aldehyde oxidoreductase, also known as MOP) from Desulfovibrio gigas belongs to the xanthine oxidase (XO) family of mononuclear molybdenum enzymes. ${ }^{1}$ The crystal structure contains a Mo coordinated by one pyranopterin, two oxo ligands, and one hydroxo/water molecule, ${ }^{\text {ld }}$ consistent with $\mathrm{X}$-ray structures of other XO family members (Chart 1). This inactive form does not contain a cyano-lysable sulfido ligand believed to be present in the active enzyme used for crystallization. However, this type of coordination is essentially the same upon resulfuration in both oxidized and reduced states. ${ }^{1 \mathrm{e}}$

The inhibition of XO by arsenite was reported over 70 years ago and has been studied extensively. ${ }^{2}$ The arsenite ion reacts at the molybdenum site, and the enzymatic activity is lost. The $\mathrm{Mo}(\mathrm{V})$ ion EPR signal obtained upon reduction of the as isolated XO incubated with arsenite was shown to have both hyperfine and quadrupole couplings of a single arsenic nucleus $(I=3 / 2)$ to $\mathrm{Mo}(\mathrm{V})(S$ $=1 / 2){ }^{2 \mathrm{a}}$ These authors propose a structure in which the arsenic and the molybdenum atoms are connected by a sulfido bridge. A similar conclusion was obtained from EXAFS studies of reduced XO samples, ${ }^{2 \mathrm{~b}}$ while other authors proposed a structure with a double bridge (oxo and sulfido). ${ }^{2 \mathrm{c}}$ This work presents the first molecular structure of an arsenite-inhibited complex of a member of the XO family and the EPR properties of a paramagnetic species detected in the reduced form of the active enzyme in the presence of arsenite.

ADH was purified from D. gigas as described by Moura et al. ${ }^{3}$ Crystals were obtained under similar conditions as reported previously. ${ }^{1 b, 4}$ After the crystals reached their maximum size, the crystallization buffer was replaced with a soaking buffer depleted of 2-propanol and containing $\mathrm{NaAsO}_{2}{ }^{4}$ A single dataset was collected at $100 \mathrm{~K}$ using synchrotron radiation. ${ }^{4}$ The reported $1.28 \AA$ resolution structure, in the inactive desulfo form, ${ }^{1 \mathrm{c}}$ stripped of water and 2-propanol molecules, was used as a starting model for refinement. The refined structure is very similar to the $1.28 \AA$ resolution structure with the exception of small details consisting mainly of different occupancies of chemical groups. Most notably, the 2-propanol molecules present in the original structure dissociate from the protein molecules apparently without destroying the crystalline lattice.

However, the replacement of the crystallization solution with a buffer depleted of 2-propanol decreases the quality of the crystals as demonstrated by the increase in the mosaicity when compared to the original crystals. Furthermore, dissociation of about half of the equivalents of molybdenum occurred. Difference Fourier electron density maps and temperature factor analysis suggest an occupancy of $60 \%$, which was subsequently used in refinement. Loss of Mo has not been observed in the crystal structures of ADH from D. gigas reported before. It has been reported, however, for

$\dagger$ Universidade Nova de Lisboa.

¥ Universidad Nacional del Litoral.
Chart 1. Schematic Structure of the Active Site in XO Family Enzymes.

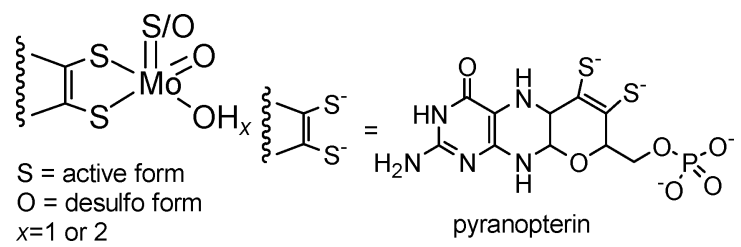

the homologous ADH from Desulfovibrio desulfuricans ${ }^{5 a}$ (the structure was refined with an occupancy of 0.5 for $\mathrm{Mo})^{5 \mathrm{~b}}$ and is common for other enzymes of the xanthine oxidase family. ${ }^{\text {a }}$ It is likely that the 2-propanol present in D. gigas ADH stabilizes its active site, preventing the loss of molybdenum. These findings give further evidence that the gorge leading away from the molybdenum is an entry/exit path of substrates and products, as has been proposed. ${ }^{1 \mathrm{~d}}$ Attempts to crystallize the complex from the native protein, in the presence of 2-propanol and arsenite, failed to show the formation of an arsenite-inhibited complex, probably due to the fact that in these experiments 2-propanol blocks the entrance pathway of the arsenite molecule.

In the initial electron density maps of the structure described here, ${ }^{6}$ density is found at $3.3 \AA$ from Mo at $3.5 \sigma$ in a weighted $2 F_{\text {o }}$ $-F_{\mathrm{c}}$ omit map. The density was modeled as an arsenic atom with three bound oxygens. It has been shown that $\mathrm{AsO}_{2}{ }^{-}$associates with water, yielding a mixture of species, i.e., $\left[\mathrm{AsO}(\mathrm{OH})_{2}\right]^{-}$, $\left[\mathrm{AsO}_{2}(\mathrm{OH})\right]^{2-}$, and $\left[\mathrm{AsO}_{3}\right]^{3-} .{ }^{7}$ The arsenite moiety is bound to the molybdenum atom through one of its oxygen atoms. One of the other oxygen atoms is found in the proximity of glutamate 869 , a conserved residue that is essential for catalysis. Figure 1 shows the geometry of the molybdenum active site and the electron density in the vicinity of the Mo center, as well as the geometry of the structure reported previously. ${ }^{1 \mathrm{c}}$

Figure 2 shows two EPR spectra of arsenite-incubated ADH samples ${ }^{4}$ reduced with an excess of dithionite, obtained at different temperatures. ${ }^{8}$ Simulation of the Mo(V) signal at $140 \mathrm{~K}$ (Figure 2) was obtained assuming an $\mathrm{Mo}(\mathrm{V})$ species $(S=1 / 2)$ coupled to an arsenic atom $(I=3 / 2)$ by both hyperfine and quadrupolar interactions. The EPR parameters show slight differences with respect to the ones obtained for $\mathrm{XO},{ }^{2 \mathrm{a}}$ which can be ascribed to slight structural changes in the active sites. These differences are not significant, indicating that the structure of the $\mathrm{Mo}(\mathrm{V})-$ arsenite complexes obtained in both enzymes are similar. Samples exchanged with buffered $\mathrm{D}_{2} \mathrm{O}$ solution showed no differences with the normal samples (not shown), which suggests that the first coordination sphere of the $\mathrm{Mo}(\mathrm{V})$ ion is not occupied by water molecules.

The $20 \mathrm{~K}$ spectrum shows, in addition to the $\mathrm{Mo}(\mathrm{V})$ signal, the EPR signal associated with the two $[2 \mathrm{Fe}-2 \mathrm{~S}]$ clusters (Fe/S I and $\mathrm{Fe} / \mathrm{S}$ II). The EPR signal associated with the $\mathrm{Mo}(\mathrm{V})$ species 


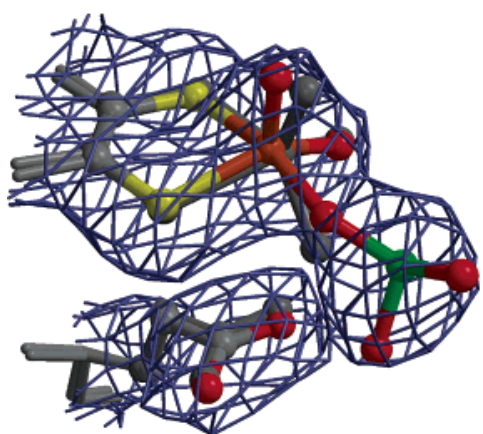

Figure 1. Geometry of the arsenite-inhibited molybdenum catalytic center. The $1.28 \AA$ resolution ADH structure ${ }^{1 c}$ is shown in gray, and the arseniteinhibited structure is color-coded (Mo in orange, As in green, C in gray, S in yellow, and $\mathrm{O}$ in red). The $\mathrm{Mo}-\mathrm{O}-\mathrm{As}$ angle is around $125^{\circ}$.

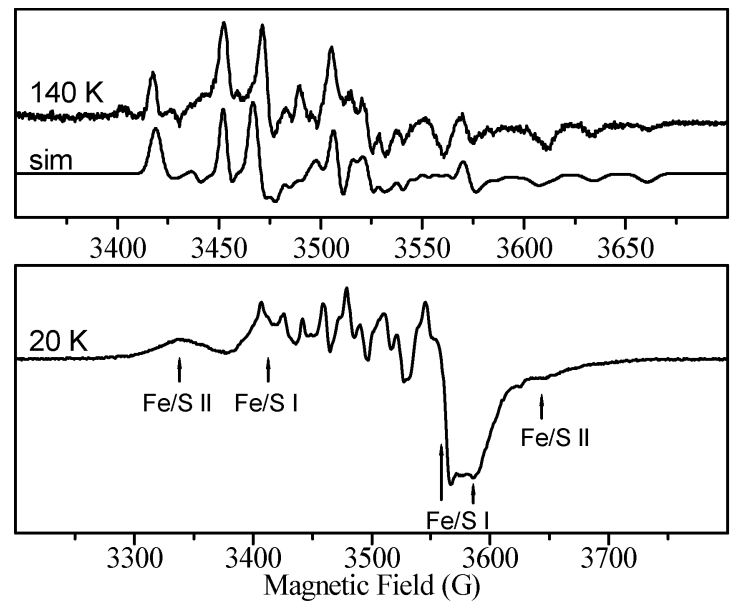

Figure 2. Arsenite-inhibited $\mathrm{ADH}$ at 140 and $20 \mathrm{~K}$ with a simulation of the high-temperature spectrum $\left(g_{1}=1.922(12), g_{2}=1.979(6), g_{3}=\right.$ 1.972(9), $\left.A_{1}=120, A_{2}=40, A_{3}=136, P_{1}=-9, P_{2}=19, P_{3}=-10\right)$. $g$-value uncertainties $= \pm 0.001$. Half-height line widths are in parentheses. $A$ and $P$ are in MHz. $g$ and $A$ tensors are assumed to be collinear, and the $P$ tensor is rotated an Euler angle $\alpha=30^{\circ}$. The simulation was performed with a Hamiltonian $H=\beta H \cdot g \cdot S+S \cdot A \cdot I+I \cdot P \cdot I$, where all symbols have their usual meaning. ${ }^{4}$

shows temperature-dependent splittings produced by magnetic coupling with $\mathrm{Fe} / \mathrm{S} \mathrm{I}$, as observed in dithionite-reduced samples of D. gigas $\mathrm{ADH} .{ }^{1 \mathrm{a}}$ The $\mathrm{Mo}(\mathrm{V})$ signal overlaps with the signal of $\mathrm{Fe} / \mathrm{S}$ I, making a clear evaluation of the EPR parameters difficult. However, the positions of the signals indicate that both Fe/S I and II signals are identical to those obtained in reduced samples of $D$. gigas $\mathrm{ADH} .^{1 \mathrm{a}, 3}$ After air reoxidation of the dithionite-reduced samples, the Fe/S cluster signals are not detectable, whereas the $\mathrm{Mo}(\mathrm{V})$ signal remains detectable, which indicates that the separation between the redox couples $(\mathrm{Mo}(\mathrm{VI})-\mathrm{Mo}(\mathrm{V})$ and $\mathrm{Mo}(\mathrm{V})-\mathrm{Mo}(\mathrm{IV}))$ is larger than that observed in normal D. gigas ADH. Figure 3 shows the saturation behavior of the $\mathrm{Mo}(\mathrm{V})$ signal at $140 \mathrm{~K}$ in reduced and air-reoxidized samples. The $\mathrm{Mo}(\mathrm{V})$ species in the presence of reduced Fe/S I are saturated at higher powers with respect to the oxidized samples, which indicates that Fe/S I not only splits the $\mathrm{Mo}(\mathrm{V})$ resonance lines but also enhances its relaxation properties.

In conclusion, we have shown that (1) arsenite coordinates to the molybdenum via an oxygen bridge in the desulfo form of the enzyme; (2) the proposed chemical pathway for electron transfer is conserved; and (3) although the presented structure represents the inactive form of the enzyme, the site of binding of the arsenite is at the position of substrate binding, indicating that the inhibition mechanism occurs through a competition with the substrate. ${ }^{1 \mathrm{e}, 9}$

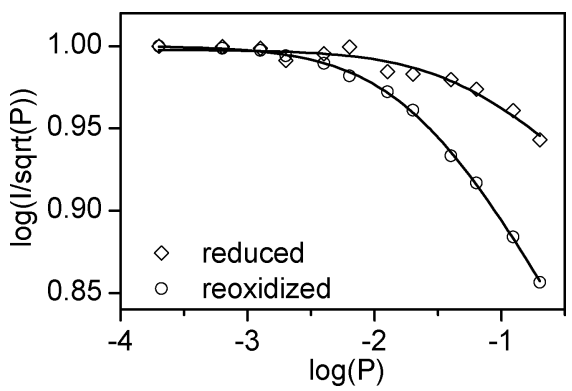

Figure 3. Normalized power dependence plot of reduced and reoxidized arsenite-inhibited EPR signal. The equation $y=P_{1}-\left(P_{2} / 2\right) \cdot \log \left(1+P / P_{3}\right)$ was fitted to the data with $P_{1}=0.998(2), P_{2}=0.15(5)$, and $P_{3}=0.05(3)$ for the reduced signal and $P_{1}=1.0002(7), P_{2}=0.279(9)$, and $P_{3}=0.021(2)$ for the reoxidized signal. The intensity of the $3450 \mathrm{G}$ peak (depicted in Figure 2) was used for the data, but all the strong peaks show the same saturation behavior. Microwave power $(P)$ is given in $\mathrm{W}$.

Furthermore, the coordination mode of the arsenite suggests that the substrate reacts with the labile water ligand of the Mo site to form a Mo-O-C bond instead of a Mo- $\mathrm{C}$ bond. ${ }^{10} \mathrm{We}$ intend to pursue further experiments to establish the relationship between the EPR properties and the geometry in the crystal structure.

Acknowledgment. We thank the Fundação para a Ciência e Tecnologia for funding A.T. (Grant SFRP/BPD/5689/2001), the European Union for funding R.B. (TMR Grant HRRN-CT-199900084), and the beamline scientists at the ID14-4 beamline of the ESRF in Grenoble (France) for assistance. Dr. S. Bursakov is thanked for help with the protein purification.

Supporting Information Available: Details on crystallization, $\mathrm{X}$-ray data collection, EPR sample preparation, and measurement and EPR signal simulation (PDF, PDB, CIF). This material is available free of charge via the Internet at http://pubs.acs.org.

\section{References}

(1) (a) Moura, J. J. G.; Barata, B. A. Methods Enzymol. 1994, 243, 24. (b) Romão, M. J.; Barata, B. A.; Archer, M.; Lobeck, K.; Moura, I.; Carrondo, M. A.; LeGall, J. Lottspeich, F.; Huber, R.; Moura, J. J. G. Eur. J. Biochem. 1993, 215, 729. (c) Rebelo, J. M.; Dias, J. M.; Huber, R.; Moura, J. J. G.; Romão, M. J. J. Biol. Inorg. Chem. 2001, 6, 791. (d) Romão, M. J.; Archer, M.; Moura, I.; Moura, J. J. G.; LeGall, J.; Engh, R.; Schneider, M.; Hof, P.; Huber, R. Science 1995, 270, 1170. (e) Huber, R.; Hof, P.; Duarte, R. O.; Moura, J. J. G.; Moura, I.; Liu, M.-Y.; LeGall, J.; Hille, R.; Archer, M.; Romão, M. J. Proc. Natl. Acad. Sci. U.S.A. 1996, 93, 8846

(2) (a) George, G. N.; Bray, R. C. Biochemistry 1983, 22, 1013. (b) Cramer, S. P.; Hille, R. J. Am. Chem. Soc. 1985, 107, 8164. (c) Hille, R.; Stewart, R. C.; Fee, J. A.; Massey, V. J. Biol. Chem. 1983, 258, 4849. (d) Barrey, G.; Bunbury, G.; Kennaway, E. L. Biochem. J. 1928, 22, 1101. (e) Couglan, M. P.; Rajagopalan, K. V.; Handler, P. J. Biol. Chem. 1969, 244, 2658. (f) Johnson, J. L.; Rajagopalan, K. V. Bioinorg. Chem. 1978, 8,439 .

(3) (a) Moura, J. J. G.; Xavier, A. V.; Bruschi, M.; LeGall, J.; Hall, D. O.; Cammack, R. Biochem. Biophys. Res. Commun. 1976, 72, 782. (b) Moura, J. J. G.; Xavier, A. V.; Cammack, R.; Hall, D. O.; Bruschi, M.; LeGall, J. Biochem. J. 1978, 173, 419

(4) See Supporting Information.

(5) (a) Duarte, R. O.; Archer, M.; Dias, J. M.; Bursakov, S.; Huber, R.; Moura, I.; Romão, M. J.; Moura, J. J. G. Biochem. Biophys. Res. Commun. 2000, 268, 745. (b) Rebelo, J.; Macieira, S.; Dias, J. M.; Huber, R.; Ascenso C. S.; Rusnak, F.; Moura, J. J. G.; Moura, I.; Romão, M. J. J. Mol. Biol. 2000, 297, 135

(6) Coordinates have been submitted to the Protein Databank (accession code 1SIJ).

(7) Loehr, T. M.; Plane, R. A. Inorg. Chem. 1968, 7, 1708.

(8) The as purified ADH from D. gigas presents a Mo(V) EPR signal normally referred to as the "resting" signal (not shown). This signal is not affected either by addition of $\mathrm{NaAsO}_{2}$ or reduction with dithionite, and contributions of this signal were subtracted in all the spectra shown.

(9) Truglio, J. J.; Theis, K.; LeimKühler, S.; Rappa, R.; Rajagopalan, K. V.; Kisker, C. Structure 2002, 10, 115

(10) (a) Howes, B. D.; Bray, R. C.; Richards, R. L.; Turner, N. A.; Bennett, B.; Lowe, D. J. Biochemistry 1996, 35, 1432. (b) Manikandan, P.; Choi, E.-Y.; Hille, R.; Hoffman, B. M. J. Am. Chem. Soc. 2001, 123, 2658.

JA0490222 